\title{
Guillain-Barré syndrome following the 2009 pandemic monovalent and seasonal trivalent influenza vaccination campaigns in Spain from 2009 to 2011: outcomes from active surveillance by a neurologist network, and records from a country-wide hospital discharge database
}

Enrique Alcalde-Cabero', Javier Almazán-Isla', Fernando J. García López', José Ramón Ara-Callizo², Fuencisla Avellanal ${ }^{1}$, Carlos Casasnovas ${ }^{3}$, Carlos Cemillán, José Ignacio Cuadrado ${ }^{5}$, Jacinto Duarte 6 , María Dolores Fernández-Pérez ${ }^{7}$, Óscar Fernández ${ }^{8}$, Juan Antonio García Merino ${ }^{9}$, Rosa García Montero ${ }^{10}$, Dolores Montero ${ }^{11}$, Julio Pardo ${ }^{12}$, Francisco Javier Rodríguez-Rivera ${ }^{13}$, María Ruiz-Tovar ${ }^{1}$, Jesús de Pedro-Cuesta ${ }^{1 *}$ and Spanish GBS Epidemiology Study Group

\footnotetext{
Abstract

Background: Studies have shown a slight excess risk in Guillain-Barré syndrome (GBS) incidence associated with $\mathrm{A}(\mathrm{H} 1 \mathrm{N1}$ )pdm09 vaccination campaign and seasonal trivalent influenza vaccine immunisations in 2009-2010. We aimed to assess the incidence of GBS as a potential adverse effect of $\mathrm{A}(\mathrm{H} 1 \mathrm{~N} 1)$ pdm09 vaccination.

Methods: A neurologist-led network, active at the neurology departments of ten general hospitals serving an adult population of 4.68 million, conducted GBS surveillance in Spain in 2009-2011. The network, established in 1996, carried out a retrospective and a prospective study to estimate monthly alarm thresholds in GBS incidence and tested them in 1998-1999 in a pilot study. Such incidence thresholds additionally to observation of GBS cases with immunisation antecedent in the 42 days prior to clinical onset were taken as alarm signals for 2009-2011, since November 2009 onwards. For purpose of surveillance, in 2009 we updated both the available centres and the populations served by the network. We also did a retrospective countrywide review of hospital-discharged patients having ICD-9-CM code 357.0 (acute infective polyneuritis) as their principal diagnosis from January 2009 to December 2011.

(Continued on next page)
}

\footnotetext{
* Correspondence: jpedro@isciii.es

${ }^{1}$ National Centre for Epidemiology, CIBERNED, Carlos III Health Institute,

Madrid, Spain

Full list of author information is available at the end of the article
}

(c) 2016 Alcalde-Cabero et al. Open Access This article is distributed under the terms of the Creative Commons Attribution 4.0 International License (http://creativecommons.org/licenses/by/4.0/, which permits unrestricted use, distribution, and reproduction in any medium, provided you give appropriate credit to the original author(s) and the source, provide a link to the Creative Commons license, and indicate if changes were made. The Creative Commons Public Domain Dedication waiver (http://creativecommons.org/publicdomain/zero/1.0/) applies to the data made available in this article, unless otherwise stated. 
(Continued from previous page)

Results: Among 141 confirmed of 148 notified cases of GBS or Miller-Fisher syndrome, Brighton 1-2 criteria in $96 \%$, not a single patient was identified with clinical onset during the 42-day time interval following A(H1N1)pdm09 vaccination. In contrast, seven cases were seen during a similar period after seasonal campaigns. Monthly incidence figures did not, however, exceed the upper $95 \% \mathrm{Cl}$ limit of expected incidence. A retrospective countrywide review of the registry of hospital-discharged patients having ICD-9-CM code 357.0 (acute infective polyneuritis) as their principal diagnosis did not suggest higher admission rates in critical months across the period December 2009-February 2010.

Conclusions: Despite limited power and underlying reporting bias in 2010-2011, an increase in GBS incidence over background GBS, associated with $\mathrm{A}(\mathrm{H} 1 \mathrm{N1})$ pdm09 monovalent or trivalent influenza immunisations, appears unlikely.

Keywords: Guillain-Barré syndrome, Influenza A virus H1N1 subtype, Influenza vaccines, Public health surveillance, Safety, ICD-9-CM

\section{Background}

Guillain-Barré syndrome (GBS) is an acute, acquired immune-mediated polyradiculoneuropathy with mainly motor symptoms, preceded in two thirds of cases by an influenza-like or respiratory tract infection (ILI-RTI) or a gastrointestinal tract infection (GTI). GBS presents with an annual incidence of 1-2/100,000 in Western countries. Although immunotherapy with intravenous gammaglobulin (IVGG) considerably reduces mortality, GBS may cause severe disability $[1,2]$.

An association between influenza vaccines and GBS was previously described in 1976 and again in 1992-1994 [3-5]. Worldwide research, mainly using self-controlled case series design [6] and self-controlled risk-interval design $[7,8]$, has addressed potential increases in GBS incidence after vaccination campaigns against the 2009 pandemic influenza $\mathrm{A}(\mathrm{H} 1 \mathrm{~N} 1)$. Three meta-analyses, one including US data obtained from six adverse event monitoring systems [9], a pooled analysis across databases from 15 countries all over the world [10], and a meta-analysis of 16 published reports [11] showed a $2-3$ fold excess risk in GBS incidence associated with $\mathrm{A}(\mathrm{H} 1 \mathrm{~N} 1) \mathrm{pdm} 09$ vaccines, both adjuvanted and non-adjuvanted, when compared to no vaccination. However, other cohort studies failed to support this association [12-14] or yielded undetermined findings [15]. Although only a US study assessed the potential increase over background GBS incidence following seasonal or $\mathrm{A}(\mathrm{H} 1 \mathrm{~N} 1) \mathrm{pdm} 09$ influenza vaccines, with negative results[16], it remains to be seen if occurrence of GBS attributed to $\mathrm{A}(\mathrm{H} 1 \mathrm{~N} 1)$ pdm09 vaccination exceeded previous seasonal and monthly GBS estimates.

This study sought to assess occurrence of GBS as a potential adverse effect of $\mathrm{A}(\mathrm{H} 1 \mathrm{~N} 1) \mathrm{pdm} 09$ or seasonal vaccinations by means of a special surveillance system established to monitor GBS incidence during the vaccination programmes.

\section{Methods}

This study consisted of two parts, namely: a prospective GBS surveillance system related to influenza vaccination, and a retrospective assessment of GBS incidence in Spain. In both parts, we attempted to detect incidence rates that were higher than previously reported.

\section{A(H1N1)pdm09 vaccine campaigns}

In Spain, influenza vaccination is offered free of charge each year to people in high-risk groups, those over 6 months old with chronic conditions, elderly people over the age of 60 or 65 years depending on the region, healthcare workers, workers in essential public services, and caregivers. The $\mathrm{A}(\mathrm{H} 1 \mathrm{~N} 1)$ pdm09 vaccine was not recommended for elderly people without chronic disease.

\section{9 seasonal trivalent influenza vaccine}

The vaccine included A/Brisbane/59/2007(H1N1), A/Brisbane/10/2007(H3N2) and B/Brisbane/60/2008 strains. In the 2009 campaign, 10.2 million doses were administered country-wide between weeks 40 to 48 .

\section{9-2010 pandemic vaccine}

The vaccine included the A/California/07/2009 (H1N1) virus strain. The vaccine brands were Focetria ${ }^{\circ}$ (Novartis), adjuvanted with MF59, recommended to children and the elderly, Pandemrix (Glaxo SmithKline), adjuvanted with ASO3, recommended for adults, and Panenza $^{\circ}$ (Sanofi Pasteur), unadjuvanted, recommended for pregnancy. Actual exposure involved administration of 970,468 doses in the second half of November 2009, 641,829 in December 2009, 114,220 in January 2010, coming to an end in late February 2010, making a total of 1.7 million doses, less than $5 \%$ of which were administered to persons under 18 years of age. In all, $12 \%$ of health care workers, $9 \%$ of workers in essential public services, $15 \%$ of people from 18 to 60 years old with chronic conditions, and $28 \%$ of people 60 years old and over received the vaccine (Division of Vaccination Programmes, Spain's Ministry of Health, Social Services, and Equality, unpublished report). 


\section{0 and 2011 campaigns}

The vaccines included the A/California/07/2009 (H1N1), A/Perth/16/2009 (H3N2) and B/Brisbane/60/2008 strains $[17,18]$, a total of 8.1 million doses in each campaign.

In terms of vaccine effectiveness, estimates in Spain suggest that the 2009-TIV had no protective effect, $\mathrm{A}(\mathrm{H} 1 \mathrm{~N} 1)$ pdm09 vaccine had a good effect (66-78 \%) and 2010-2011TIVs had a lower effect (50-55 \%) [17-19].

\section{Neurologist network}

An 11-hospital neurologist network, conceived as a special surveillance system [20], was established in 1996 to set alarm thresholds in GBS monthly incidence, so that incidence monitoring could be undertaken in situations where risk was perceived. The National Centre for Epidemiology at the Carlos III Institute of Health in Madrid coordinated the network, which then covered an adult population of 3.9 million. People under 20 years were not covered. The network incorporated epidemiological features of GBS in adults from 1985 to 1997 to estimate upper limits in monthly incidences, and then conducted a 2-year pilot prospective study to update upper thresholds in 1998-1999. As a result, the network estimated curves with expected monthly incidences for all and certain age groups [21, 22].

\section{Surveillance design}

At the request of the Spanish Agency of Medicines and Medical Devices (Agencia Española de Medicamentos y Productos Sanitarios/AEMPS), the National Centre for Epidemiology, acting as a Central Unit, contacted network members in August 2009 and re-established the network to detect a potential GBS outbreak related to $\mathrm{A}(\mathrm{H} 1 \mathrm{~N} 1) \mathrm{pdm} 09$ vaccination. The eleven hospitals constituting the original network remained functionally appropriate for surveillance with minor changes in referral, staff and catchment population but one hospital which had difficulties in notifying cases was excluded. In Spain, a national health service covers the majority of population. To estimate incidence rates, each participant hospital updated the number of people it covered. Of a total of 36.9 million Spanish residents aged $\geq 20$ years, the population under surveillance numbered 4.68 million, approximately $1 / 8$ of the country population of that age. Prospective notification to the Central Unit of all patients suspected of presenting with GBS started in September 2009, approximately one month before onset of the $\mathrm{A}(\mathrm{H} 1 \mathrm{~N} 1)$ monovalent vaccine campaign, and ended on 31 December 2011. Retrospective reporting dated back to 1 January 2009. The Central Unit was tasked with identifying potential outbreaks on the basis of the information supplied by local neurologists, and, when applicable, notifying these to the AEMPS.

\section{Study subjects}

A GBS case was defined by reference to the National Institutes of Neurological Disorders and Stroke (NINDS) criteria [23]. Two months after notification of a suspected case of GBS, local neurologists confirmed or excluded the diagnosis on the basis of clinical, neurophysiological or cerebrospinal fluid parameters. Miller-Fisher syndrome (MFS) was not compulsorily reported. Each GBS or MFS case was re-classified at the end of the 36-month study by one local neurologist and JdP-C, at the Central Unit, using the recent and prevailing Brighton Collaboration casedefinition categories [23, 24].

The AEMPS checked the presence of other possible GBS cases reported as suspected adverse drug reactions in the population covered by network hospitals. For data-completion purposes, in 2012 we requested all hospital pharmacies to provide information on registered IVGG deliveries to wards for treatment of GBS patients admitted during the period 2009-2012. These requests did not add any new patient.

\section{Clinical antecedents}

We collected information on immunisations, including influenza vaccines, administered during the 42-day period preceding clinical onset of suspected GBS. For other clinical antecedents, we only investigated those occurring during the 30-day period prior to clinical onset of suspected GBS, namely, respiratory infections (fever with cough or expectoration and other respiratory symptoms), gastrointestinal infections (nausea, vomiting, diarrhoea), other infections, and other antecedents. We collected antecedents through interviews with patients. The AEMPS, working in collaboration with the public health authorities, would certify the vaccine received (brand, health centre where the prescription was issued, and administration date) in $\mathrm{A}(\mathrm{H} 1 \mathrm{~N} 1) \mathrm{pdm} 09$ post-vaccination cases.

\section{Database of hospital discharges}

At the end of 2013, we requested the National Hospital Inpatient Registry to supply us with data on all patients aged $\geq 20$ years admitted in the period 2009-2011 and having International Classification of Diseases, Ninth Revision, Clinical Modification (ICD-9-CM) code 357.0 (acute infective polyneuritis) as their principal or other diagnosis at discharge. This registry constitutes a database on discharges generated at all hospitals serving the Spanish National Health Service, which provides services for the large majority of the resident population country-wide and encompasses all hospitals in the surveillance network [25].

\section{Ethical approval}

This study was approved by the Research Ethics Committee at the Carlos III Institute of Health. All patients, with no exceptions, gave their informed consent. 


\section{Statistical analysis}

We computed exact Poisson confidence intervals (CI) for observed incidence rates for all, age groups, and genders [26]. We accepted as valid the background incidence and threshold values obtained from the previous study in 1998-1999, despite a possible change in hospital admissions due to the widespread use of IVGG as early treatment for GBS, including mild cases. We defined alarm signals when post A(H1N1)pdm09 immunisation cases were notified by the network or the total monthly incidence exceeded the estimated monthly upper $95 \%$ CI limit for background incidence [22]. Monthly upper 95 \% CI limit for background incidence had been calculated with ARIMA and Poisson models [21]. Crude monthly incidences were calculated from notifications and confirmed cases, and plotted on a graph showing predicted values.

We checked the positive predictive value of ICD-9CM diagnostic code 357.0 in the Hospital In-patient Registry against the judgment of a neurologist (JAG-M) at one of the hospitals, the Puerta de Hierro University Hospital in Majadahonda. For each centre, we estimated a sensitivity value as the complementary of the falsenegative rate, defined as the ratio between the number of notified and confirmed GBS cases not registered at the National Hospital In-patient Registry over the total number of notified and confirmed GBS cases. We calculated monthly incidences of hospital-admitted GBS country-wide and plotted these on the epidemic curve defined by the $95 \%$ CI limits of expected incidences depicted in the above-mentioned graph.

\section{Results}

GBS cases ascertained by the neurologist network

Figure 1 shows the geographical distribution of the 10 hospitals in the network. During the surveillance period, January 2009-December 2011, local neurologists notified 148 patients with suspected GBS to the Central Unit. Of these, 138 were confirmed as GBS and three as MFS, making a total of 141 diagnoses confirmed by reference to the NINDS criteria after a minimum follow-up of one month. The positive predictive value of a suspected or notified case was 141/148, $95 \%, 95 \%$ CI $90 \%$ to $98 \%$. When patients were re-classified according to Brighton criteria, 81 (57\%), 54 (38\%), and 5 (4\%) met criteria for levels 1,2 and 3, respectively; one case (0.7 \%) remained unclassified due to lack of access to hospital records. Of the seven patients excluded from the initially reported total of 148, three had alternative neurological diagnoses and four had a doubtful GBS diagnosis.

Of the 141 cases, 82 (58 \%) were men; mean age at onset was 55.9 years (standard deviation 17.28 years); and 48 patients (34\%) were bed-bound one week after onset (Table 1). Two patients with serious comorbidity died within the first week of onset and a further four at a later date.

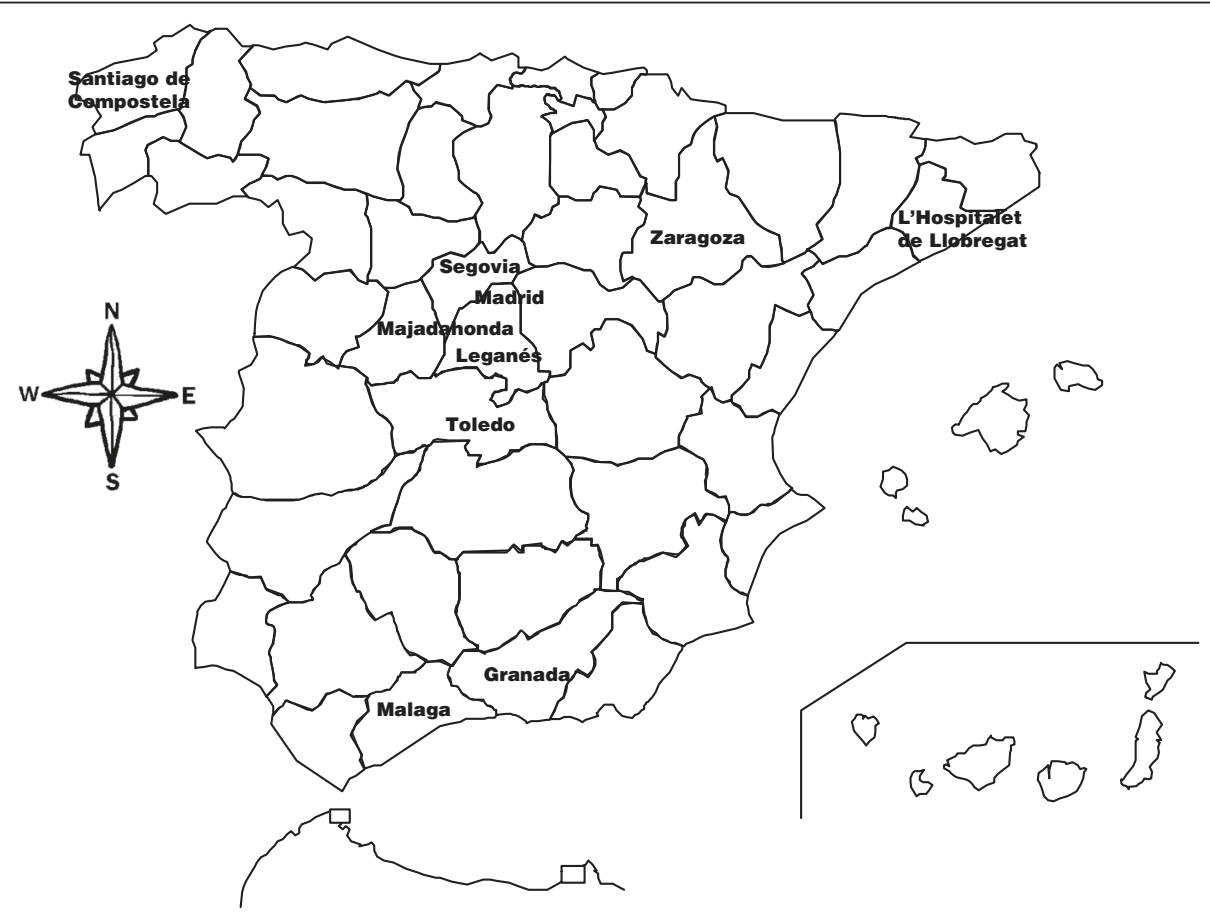

Fig. 1 Geographical distribution of cities where study hospitals provided neurological care for Guillain-Barré syndrome. The inset shows Canary Islands. This figure is slightly modified from Cuadrado et al. [22]. Copyright 2004, with permission of Springer 
Table 1 Characteristics of confirmed GBS cases notified in 2009-2011 and identified by the neurologist network

\begin{tabular}{|c|c|c|c|c|c|c|}
\hline \multirow[b]{2}{*}{ Variables } & \multirow[b]{2}{*}{ No. of patients (\%) } & \multicolumn{5}{|c|}{ Motor status at one week after clinical onset or hospital admission } \\
\hline & & Independent gait & Gait: able with support & Able to stand up & Bed-bound & Unknown \\
\hline \multicolumn{7}{|l|}{ Sex } \\
\hline Male & $82(58.2)$ & 21 & 21 & 3 & 31 & 6 \\
\hline Female & $59(41.8)$ & 18 & 22 & 0 & 17 & 2 \\
\hline \multicolumn{7}{|l|}{ Age group (years) } \\
\hline $20-29$ & $11(7.8)$ & 5 & 4 & 0 & 1 & 1 \\
\hline $30-39$ & $23(16.3)$ & 14 & 6 & 0 & 2 & 1 \\
\hline $40-49$ & $21(14.9)$ & 5 & 9 & 1 & 5 & 1 \\
\hline $50-59$ & $25(17.7)$ & 4 & 13 & 1 & 6 & 1 \\
\hline $60-69$ & $24(17.0)$ & 6 & 5 & 0 & 12 & 1 \\
\hline $70-79$ & $26(18.4)$ & 2 & 4 & 0 & 17 & 3 \\
\hline $80+$ & $11(7.8)$ & 3 & 2 & 1 & 5 & 0 \\
\hline \multicolumn{7}{|l|}{ Clinical antecedent } \\
\hline Not identified & $41(29.1)$ & 14 & 13 & 1 & 9 & 4 \\
\hline Recorded & $100(70.9)$ & 25 & 30 & 2 & 39 & 4 \\
\hline Infection & $85(60.3)$ & 21 & 27 & 2 & 32 & 3 \\
\hline$-\mathrm{GTI}$ & $40(28.4)$ & 9 & 13 & 1 & 15 & 2 \\
\hline -ILI-RTI & $34(24.1)$ & 11 & 9 & 1 & 12 & 1 \\
\hline —GI and ILI-RTI & $3(2.1)$ & 0 & 1 & 0 & 2 & 0 \\
\hline -Urinary tract & $3(2.1)$ & 0 & 2 & 0 & 1 & 0 \\
\hline -Other & $4(2.8)$ & 1 & 2 & 0 & 1 & 0 \\
\hline —Unknown & $1(0.7)$ & 0 & 0 & 0 & 1 & 0 \\
\hline Influenza vaccination & $7(5.0)$ & 2 & 1 & 0 & 4 & 0 \\
\hline Other ${ }^{a}$ & $13(9.2)$ & 2 & 4 & 0 & 6 & 1 \\
\hline All patients & $141^{a, b}$ & $39(27.7)$ & $43^{b}(30.5)$ & $3(2.1)$ & $48^{\mathrm{b}}(34.0)$ & $8(5.7)$ \\
\hline
\end{tabular}

GBS Guillain-Barré syndrome, GTI gastrointestinal tract infection, ILI-RTI influenza-like infection or respiratory tract infection

a"Other" encompasses surgery, medication, trauma, gastric carcinoma, delivery and pregnancy

${ }^{\text {b}}$ The sum does not add up the total amount of patients because some patients had more than one antecedent

\section{GBS incidence according to the neurologist network}

Table 2 shows the age- and sex-specific distribution of cases and incidences. The annual incidence per 100,000 adult population was 1.20 for men and 0.81 for women. Incidence increased with age, particularly among men, up to the 70-79 age group. Table 3 shows the distribution of cases and incidence by hospital. Average annual incidence per 100,000 ranged from 0.35 in Malaga to 2.51 in Santiago de Compostela.

\section{GBS cases registered at the National Hospital In-patient Registry}

A total of 2383 patients were hospital-admitted countrywide from 2009 to 2011 with ICD-9-CM code 357.0 as their principal diagnosis. The number of registered patients with GBS admitted to the networked hospitals across the period 2009-2011 was 193, 37 \% higher than the 141 notified and confirmed GBS and MFS cases, with a several-fold variation in incidence among hospitals. Thirty-five out of the 141 patients with confirmed GBS reported by surveillance from 2009 to 2011 (25\%) were not identified among those with GBS code 357.0 as their principal diagnosis (sensitivity $75 \%$, $95 \%$ CI $67 \%$ to $82 \%$ ). Likewise, the neurologist network reported 106 out of the 193 patients who were registered as admitted from 2009 to 2011 to networked hospitals and discharged with code 357.0.

The validation of ICD-9-CM code 357.0 for GBS diagnosis, recorded for 17 patients at the Puerta de Hierro Hospital in Majadahonda, showed it to be wrong in three cases, $18 \%$, which had in fact been diagnosed with axonal polyneuropathy, chronic transformation of a previous GBS and non-inflammatory polyradiculoneuropathy attributable to causes other than GBS. Hence, the positive predictive value of such 357.0 coded diagnosis was $82 \%, 95 \%$ CI $57 \%$ to $96 \%$. 
Table 2 Observed incidence of GBS per 100,000 person-years for 2009-2011 in the population of 4.68 million under surveillance by the neurologist network

\begin{tabular}{|c|c|c|c|c|c|c|c|c|c|c|c|c|}
\hline \multirow[b]{2}{*}{ Age group in years } & \multicolumn{4}{|l|}{ Male } & \multicolumn{4}{|c|}{ Female } & \multicolumn{4}{|l|}{ Total } \\
\hline & Cases & Person-years & Incidence & $95 \% \mathrm{Cl}$ & Cases & Person-years & Incidence & $95 \% \mathrm{Cl}$ & Cases & Person-years & Incidence & $95 \% \mathrm{Cl}$ \\
\hline $20-29$ & 6 & $1,232,652$ & 0.49 & $(0.18-1.06)$ & 5 & $1,224,264$ & 0.41 & $(0.13-0.95)$ & 11 & $2,456,916$ & 0.45 & $(0.22-0.80)$ \\
\hline $30-39$ & 12 & $1,607,871$ & 0.75 & $(0.39-1.30)$ & 11 & $1,560,600$ & 0.70 & $(0.35-1.26)$ & 23 & $3,168,471$ & 0.73 & $(0.46-1.09)$ \\
\hline $40-49$ & 14 & $1,350,147$ & 1.04 & $(0.57-1.74)$ & 7 & $1,354,077$ & 0.52 & $(0.21-1.07)$ & 21 & $2,704,224$ & 0.78 & $(0.48-1.19)$ \\
\hline $50-59$ & 10 & 991,665 & 1.01 & $(0.48-1.85)$ & 15 & $1,045,449$ & 1.43 & $(0.80-2.37)$ & 25 & $2,037,114$ & 1.23 & $(0.79-1.81)$ \\
\hline $60-69$ & 17 & 783,156 & 2.17 & $(1.26-3.48)$ & 7 & 845,904 & 0.83 & $(0.33-1.71)$ & 24 & $1,629,060$ & 1.47 & $(0.94-2.19)$ \\
\hline $70-79$ & 14 & 569,067 & 2.46 & $(1.34-4.13)$ & 12 & 712,188 & 1.68 & $(0.87-2.94)$ & 26 & $1,281,255$ & 2.03 & $(1.33-2.97)$ \\
\hline $80+$ & 9 & 272,355 & 3.30 & $(1.51-6.27)$ & 2 & 503,019 & 0.40 & $(0.05-1.44)$ & 11 & 775,374 & 1.42 & $(0.71-2.54)$ \\
\hline Total $\geq 20$ years & 82 & $6,806,913$ & 1.20 & $(0.96-1.50)$ & 59 & $7,245,501$ & 0.81 & $(0.62-1.05)$ & 141 & $14,052,414$ & 1.00 & $(0.84-1.18)$ \\
\hline
\end{tabular}

GBS indicates Guillain-Barré syndrome, $\mathrm{Cl}$ confidence interval 
Table 3 Hospitals and population coverage in numbers, GBS patients notified to the neurologist network, estimated sensitivity compared to patients coded as GBS in the National Hospital In-patient Registry and incidence $\times 100,000$

\begin{tabular}{|c|c|c|c|c|c|c|c|c|c|c|c|}
\hline \multirow[t]{2}{*}{ Hospital } & \multirow{2}{*}{$\begin{array}{l}\text { Person-years } \\
\geq 20 \text { years }\end{array}$} & \multicolumn{6}{|l|}{ Number of patients } & \multicolumn{2}{|l|}{ Proportions } & \multicolumn{2}{|c|}{ Incidence $\times 100,000$} \\
\hline & & $\begin{array}{c}\text { Number of } \\
\text { hospital-registered } \\
\text { patients }^{\mathrm{a}}\end{array}$ & $\begin{array}{l}\text { Notified } \\
\text { patients }\end{array}$ & $\begin{array}{l}\text { Notified and } \\
\text { confirmed GBS } \\
\text { (a) }\end{array}$ & $\begin{array}{l}\text { Confirmed } \\
\text { not hospital } \\
\text { registered (b) }\end{array}$ & $\begin{array}{l}\text { Infection in } \\
\text { preceding } \\
30 \text { days }\end{array}$ & $\begin{array}{l}\text { Influenza vaccine } \\
\text { in preceding } \\
42 \text { days }\end{array}$ & $\begin{array}{l}\text { Confirmed not } \\
\text { registered over notified } \\
\text { and confirmed (b/a) }\end{array}$ & $\begin{array}{l}\text { Estimated } \\
\text { sensitivity } \\
1-(\mathrm{b} / \mathrm{a})\end{array}$ & $\begin{array}{l}\text { in } \\
\text { registered } \\
\text { patients }^{\mathrm{a}}\end{array}$ & $\begin{array}{c}\text { in } \\
\text { notified } \\
\text { patients }\end{array}$ \\
\hline $\begin{array}{l}\text { Carlos Haya Hospital } \\
\text { (Malaga) }\end{array}$ & $3,676,698$ & 19 & 13 & 13 & 4 & 8 & 0 & 0.31 & 0.69 & 0.52 & 0.35 \\
\hline $\begin{array}{l}\text { General Hospital } \\
\text { (Segovia) }\end{array}$ & 364,983 & 6 & 4 & 4 & 0 & 3 & 0 & 0.00 & 1.00 & 1.64 & 1.10 \\
\hline $\begin{array}{l}\text { La Paz University } \\
\text { Hospital (Madrid) }\end{array}$ & $1,239,486$ & 27 & 19 & 18 & 5 & 10 & 2 & 0.28 & 0.72 & 2.18 & 1.45 \\
\hline $\begin{array}{l}\text { Miguel Servet University } \\
\text { Hospital (Zaragoza) }\end{array}$ & $1,023,261$ & 13 & 11 & 9 & 1 & 3 & 0 & 0.11 & 0.89 & 1.27 & 0.88 \\
\hline $\begin{array}{l}\text { Bellvitge University } \\
\text { Hospital (Hospitalet } \\
\text { de Llobregat) }\end{array}$ & $3,034,845$ & 31 & 20 & 20 & 7 & 11 & 2 & 0.35 & 0.65 & 1.02 & 0.66 \\
\hline $\begin{array}{l}\text { Puerta de Hierro } \\
\text { University Hospital } \\
\text { (Majadahonda) }\end{array}$ & 967,029 & 17 & 15 & 14 & 0 & 8 & 0 & 0.00 & 1.00 & 1.76 & 1.45 \\
\hline $\begin{array}{l}\text { Severo Ochoa University } \\
\text { Hospital (Leganés) }\end{array}$ & 472,563 & 8 & 5 & 5 & 0 & 3 & 0 & 0.00 & 1.00 & 1.69 & 1.06 \\
\hline $\begin{array}{l}\text { Virgen de la Salud } \\
\text { Hospital (Toledo) }\end{array}$ & $1,003,170$ & 16 & 17 & 16 & 6 & 11 & 0 & 0.38 & 0.63 & 1.59 & 1.59 \\
\hline $\begin{array}{l}\text { Virgen de las Nieves } \\
\text { University Hospital } \\
\text { (Granada) }\end{array}$ & $1,115,721$ & 18 & 15 & 13 & 4 & 8 & 0 & 0.31 & 0.69 & 1.61 & 1.17 \\
\hline $\begin{array}{l}\text { University Hospital } \\
\text { Clínico (Santiago } \\
\text { de Compostela) }\end{array}$ & $1,154,658$ & 38 & 29 & 29 & 8 & 20 & 3 & 0.28 & 0.72 & 3.29 & 2.51 \\
\hline Total & $14,052,414$ & 193 & 148 & 141 & 35 & 85 & 7 & 0.25 & 0.75 & 1.37 & 1.00 \\
\hline
\end{tabular}

GBS Guillain-Barré syndrome

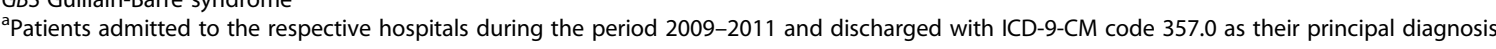




\section{Vaccination and other antecedents}

One hundred cases (71 \%) had a record of potential exposures (Table 1), with 85 (60\%) patients having had infections, 7 (5\%) having received immunisations with influenza vaccine within the 42 days prior to clinical onset and 13 (9\%) having other antecedents.

Table 4 shows demographic and clinical data for the seven cases with vaccination, who were admitted to three different hospitals. All cases fulfilled Brighton level-1 criteria. Four had received a 2009-TIV prior to A(H1N1)pdm09 campaign, and one of these was simultaneously affected by a bronchopulmonary infection as a clinical antecedent. None had received A(H1N1)pdm09 vaccine. Another three cases had received a 2010-2011TIV immunisation containing the $\mathrm{A}(\mathrm{H} 1 \mathrm{~N} 1) \mathrm{pdm} 09$ strain, one in the 2010 campaign and two in 2011. Four out of seven GBS cases preceded by influenza vaccination were bed-bound compared with 43 of 134 other GBS cases (Tables 1 and 4).

As no GBS case related to $\mathrm{A}(\mathrm{H} 1 \mathrm{~N} 1) \mathrm{pdm} 09$ vaccination was found we did not send any alarm signal to health authority, the AEMPS.

Figure 2 depicts the monthly/seasonal incidence of GBS in patients grouped by age and type of most

Table 4 Neurologist network: demographic and clinical data pertaining to seven GBS patients with influenza immunisations during the 42-day period preceding clinical onset

\begin{tabular}{|c|c|c|c|c|c|c|c|}
\hline $\begin{array}{l}\text { Patient ref. } \\
\text { no., sex, } \\
\text { age }\end{array}$ & $\begin{array}{l}\text { Vaccination date } \\
\text { and type (a) }\end{array}$ & $\begin{array}{l}\text { Co-morbidity or clinical } \\
\text { antecedent in } 30 \text { days } \\
\text { prior to onset }\end{array}$ & $\begin{array}{l}\text { Symptom } \\
\text { onset (b) }\end{array}$ & $\begin{array}{l}\text { (a-b) Interval } \\
\text { in weeks }\end{array}$ & $\begin{array}{l}\text { Functional } \\
\text { level at } \\
\text { one week }\end{array}$ & Treatment & $\begin{array}{l}\text { Clinical confirmation } \\
\text { on the basis of }\end{array}$ \\
\hline \multirow{4}{*}{$\begin{array}{l}1 \\
\text { Female } \\
53\end{array}$} & 2 Oct 2009 & \multirow[t]{4}{*}{ Motor neurone disease } & \multirow[t]{4}{*}{13 Oct 2009} & \multirow[t]{4}{*}{$1-2$} & \multirow[t]{4}{*}{ Walking } & \multirow[t]{4}{*}{ Not treated } & $\begin{array}{l}\text { Clinical symptoms/ } \\
\text { exam. }\end{array}$ \\
\hline & \multirow[t]{3}{*}{ 2009-TIV } & & & & & & $\begin{array}{l}\text { Cerebrospinal fluid } \\
\text { (CSF) tests }\end{array}$ \\
\hline & & & & & & & Electrophysiology lab. \\
\hline & & & & & & & Other causes excluded \\
\hline \multirow{2}{*}{$\begin{array}{l}2 \\
\text { Male } \\
68\end{array}$} & 27 Oct 2009 & Heart disease. & \multirow[t]{2}{*}{22 Nov 2009} & \multirow[t]{2}{*}{$3-4$} & \multirow[t]{2}{*}{ Bed-bound } & \multirow[t]{2}{*}{ IVGG } & Electrophysiology lab. \\
\hline & 2009-TIV & $\begin{array}{l}\text { Sleep apnea. High blood } \\
\text { pressure. Bronchopulmonary } \\
\text { infection }\end{array}$ & & & & & Other causes excluded \\
\hline \multirow{2}{*}{$\begin{array}{l}3 \\
\text { Male } \\
34\end{array}$} & 20 Oct 2009 & \multirow[t]{2}{*}{ Syphilis seropositive } & \multirow[t]{2}{*}{30 Nov 2009} & \multirow[t]{2}{*}{$5-6$} & \multirow[t]{2}{*}{ Walking } & \multirow[t]{2}{*}{ IVGG } & $\begin{array}{l}\text { Clinical symptoms/ } \\
\text { exam. }\end{array}$ \\
\hline & 2009-TIV & & & & & & CSF tests \\
\hline
\end{tabular}

\begin{tabular}{|c|c|c|c|c|c|c|c|}
\hline & & & & & & & $\begin{array}{l}\text { Electrophysiology lab. } \\
\text { Other causes excluded }\end{array}$ \\
\hline \multirow{4}{*}{$\begin{array}{l}4 \\
\text { Male } \\
70\end{array}$} & 28 Sept 2009 & Motor neurone disease & 10 Oct 2009 & $1-2$ & Bed-bound & IVGG & $\begin{array}{l}\text { Clinical symptoms/ } \\
\text { exam }\end{array}$ \\
\hline & 2009-TIV & & & & & & CSF tests \\
\hline & & & & & & & Electrophysiology lab. \\
\hline & & & & & & & Other causes excluded \\
\hline \multirow{2}{*}{$\begin{array}{l}5 \\
\text { Male } \\
77\end{array}$} & 18 Oct 2010 & - & 1 Nov 2010 & 2 & Bed-bound & IVGG & $\begin{array}{l}\text { Clinical symptoms/ } \\
\text { exam. }\end{array}$ \\
\hline & 2010-2011-TIV ${ }^{a}$ & & & & & & $\begin{array}{l}\text { Electrophysiology lab. } \\
\text { Other causes excluded }\end{array}$ \\
\hline \multirow{3}{*}{$\begin{array}{l}6 \\
\text { Female } \\
78\end{array}$} & 5 Jan 2011 & - & 15 Jan 2011 & $1-2$ & $\begin{array}{l}\text { Able to walk } \\
\text { with support }\end{array}$ & IVGG & $\begin{array}{l}\text { Clinical symptoms/ } \\
\text { exam. }\end{array}$ \\
\hline & 2010-2011-TIV & & & & & & CSF tests \\
\hline & & & & & & & $\begin{array}{l}\text { Electrophysiology lab. } \\
\text { Other causes excluded }\end{array}$ \\
\hline \multirow{3}{*}{$\begin{array}{l}7 \\
\text { Male } \\
82\end{array}$} & 27 Oct 2011 & High blood pressure & 23 Nov 2011 & 4 & Bed-bound & $\begin{array}{l}\text { IVGG } \\
\text { Mechanical }\end{array}$ & $\begin{array}{l}\text { Clinical symptoms/ } \\
\text { exam. }\end{array}$ \\
\hline & 2010-2011-TIV & $\mathrm{DM}$ & & & & Ventilation & CSF tests \\
\hline & & Atrial fibrillation & & & & & $\begin{array}{l}\text { Electrophysiology lab. } \\
\text { Other causes excluded }\end{array}$ \\
\hline
\end{tabular}



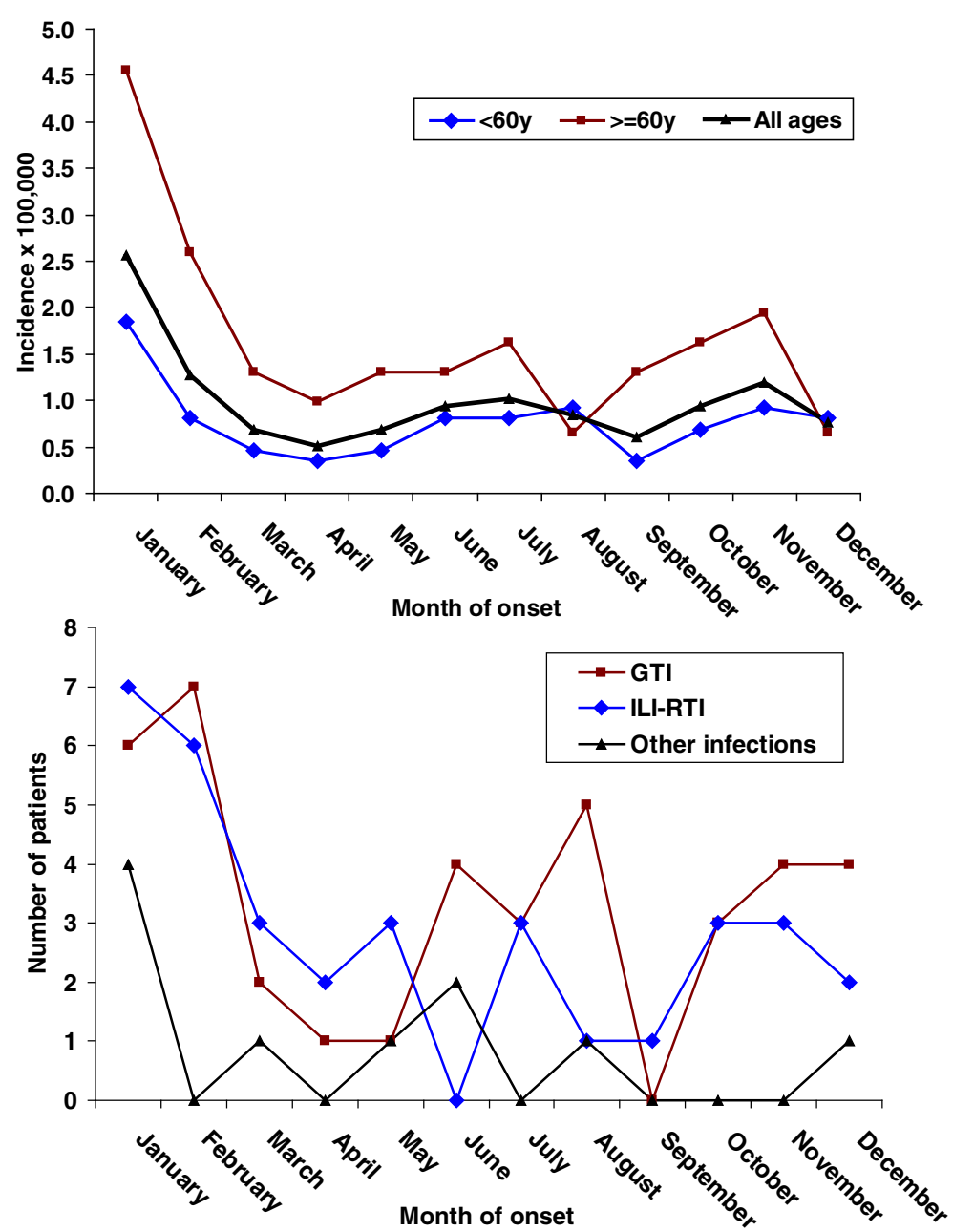

Fig. 2 Seasonal patterns of Guillain-Barré syndrome (GBS) according to the neurologist network. Top: monthly incidence of GBS in two age groups. Bottom: case distribution by type of preceding infection and month of clinical onset

frequent antecedent. The seasonal distribution suggested the highest incidence in January and February, particularly for patients aged $\geq 60$ years and for those with previous ILI-RTI or GTI.

\section{9-2011 GBS incidence compared with background incidence}

Figure 3 gives an overview of the incidence and antecedents during the surveillance period compared to the predicted background incidence. Monthly incidences of notified and confirmed GBS did not exceed the $95 \%$ upper confidence limit but did exceed the lower limit several times in 2010 and 2011. GBS rates from National Hospital In-patient Registry were generally higher than those calculated from notified patients, particularly after the 2010-2011-TIV campaign, and occasionally exceeded the upper limit of the epidemic prediction, though not for the period October-November 2009 when the four
post-2009-TIV cases were observed or the period following the $\mathrm{A}(\mathrm{H} 1 \mathrm{~N} 1) \mathrm{pdm} 09$ vaccination campaign.

\section{Discussion}

The performance of our surveillance of GBS as a potential adverse reaction of influenza immunisations rests on the coincidence of time-related clustering of GBS cases occurring within the 42-day, high-risk post-immunisation period with a greater-than-expected increase in GBS incidence. Overall, monthly incidence of GBS, whether notified or registered country-wide, does not appear to reflect any impact of $\mathrm{A}(\mathrm{H} 1 \mathrm{~N} 1) \mathrm{pdm} 09$ or seasonal vaccine campaigns. Our neurologist network failed to find a single GBS case following A(H1N1)pdm09 vaccination. The Hospital In-patient Registry suggested no increase in GBS monthly incidence during or post influenza immunisation campaigns.

Our study might have some limitations. The power of this study to detect an increase in incidence in vaccinated 


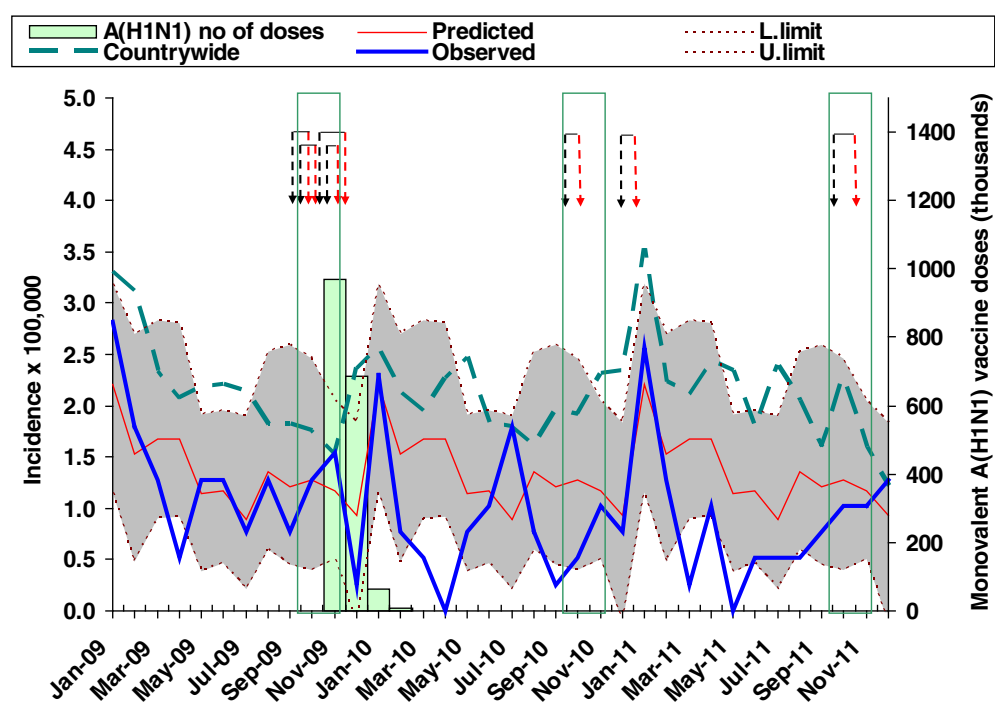

Fig. 3 Predicted Guillain-Barré syndrome (GBS) background incidence with its 95 \% confidence limits; monthly incidence of GBS among the population under surveillance as observed by the neurologist network during the period 2009-2010, seasonal and A(H1N1)pdm09 influenza vaccination campaigns (in the latter case with monthly number of doses for the whole population from 16 November 2009 to 1 February 2010, and routine campaign intervals —-marked between vertical green lines_-for seasonal immunisations), clinical antecedents (black arrows) and clinical onset of GBS patients (red arrows) immunised during the 42-day prior to clinical onset; and monthly incidence of GBS during the surveillance period, as seen from country-wide diagnostic data on 2383 hospital-admitted patients over 20 years and having GBS coded as ICD-9-CM 357.0 as their principal diagnosis at discharge (Discharge Certificates, National In-Patient Hospital Registry)

persons depends on the method of determination of the threshold, on the relative risk of GBS in vaccinated persons, and on the proportion of the population that received the vaccine. Since only a small part of the population was vaccinated with $\mathrm{A}(\mathrm{H} 1 \mathrm{~N} 1) \mathrm{pdm} 09$, the relative risk associated with vaccination should have been very high to induce an overall incidence of GBS sufficiently high to exceed the threshold. However, we did not find any $\mathrm{GBS}$ case following $\mathrm{A}(\mathrm{H} 1 \mathrm{~N} 1) \mathrm{pdm} 09$ vaccination in the 165,000 population vaccinated, despite an expected background incidence around 2.62 cases from December to March, which makes increased incidence associated with vaccination highly unlikely. Another limitation is the difficulty in adjusting for confounding from causes such as ILI-RTI or GTI, both of which are unlikely in our series in the light of the lack of such antecedents in six of our seven cases. Furthermore, potential underreporting might have happened, as has been suggested in connection with paediatric and medical departments in Sweden, where a similar GBS surveillance system was in place [27]. In our study, only one reported GBS case was not hospitaladmitted but similar cases may have been overlooked. Underreporting in autumn 2009, linked to considerable media attention paid to influenza-related events during the influenza monovalent vaccine campaign, was probably lower than during other surveillance periods. Additionally, National Hospital In-patient Register has a proportion of false positive and false negative cases whose impact on this registry's ultimate validity for estimating all GBS cases is uncertain [28]. Likewise, we assumed that background incidence estimated in 1999 would remain the same 10 years later, despite the potential change in infection transmissibility caused by the increase in population density in Spain over this period. Neither can exposure misclassification be ruled out since recall bias might have affected vaccination ascertainment. Our study also lacks power to study the individual effects of every vaccine adjuvant. Lastly, one of the post-2009-TIV Spanish cases had preceding ILI-RTI episodes, and two others had motor function potentially compromised by motor neurone disease. One could thus speculate that co-morbidity may have contributed to vaccination being indicated. High immunisation frequencies and improved information might have mimicked excess post-2009-TIV GBS among the surveillance population in both Spain and the United Kingdom [29].

Our results are consistent with a study by Burwen et al. [16] on GBS incidence after influenza vaccination among the Medicare population in 2009-2010, which failed to find an increase in GBS incidence above a critical limit established by GBS incidence in the previous five years. In contrast, our results differ from the modest risk excess reported in three pooled analyses [9-11]. However, the main design of these reviews, namely, selfcontrolled case series analysis and self-controlled interval-risk design, might imply a high risk of bias, i.e., recall bias for exposures predating GBS onset by more than 42 days and, in particular, incomplete adjustment 
for potential confounders like ILI-RTI or GTI and seasonal patterns of GBS onset [30,31]. On the other hand, cohort studies either give lower relative risks [11, 15, 32] or fail to find any association [12-14].

Contrary to the findings of the ITANG study, which used a 176-patient case-control and case-series designs and reported modest but positive associations with 2010-TIV [33], we failed to observe any suspected impact of either the 2010 or the 2011 seasonal immunisation. Doubts nevertheless continue to surround ITANG's capacity to remove residual confounding from the several-fold higher effect of the preceding infections, odds ratio $(\mathrm{OR})=23.8$ and $\mathrm{OR}=11.5$ for ILI-RTI or GTI, respectively. Even so, the most important reason for suspecting a high risk of bias in the ITANG study is control selection towards low 2010-2011-TIV immunisation rates in hospital controls. ITANG controls were recruited from among patients with trauma, after eliminating those with chronic conditions, a selection strategy that would potentially exclude people in whom 2010-2011-TIV had been indicated.

One important aspect of our results regarding the four cases associated with the 2009-TIV and not with preceding infections is that they might match the intriguing association observed in the UK for the same exposure and time as reported by the VAESCO study. The VAESCO study reported an excess GBS risk for the unadjuvanted 2009-TIV in the UK [34], not seen in previous years using the same UK database [29]. The fact that such an effect was not observed in other seasonal influenza vaccines in 2010 or 2011 in Spain might point to a side-effect of the 2009-TIV due either to the A/Brisbane/59/2007(H1N1) or to the A/Brisbane/10/2007(H3N2) component of the 2009 TIV being removed from the 2010-2011-TIV.

Our study design, when compared to the other three procedures used to monitor or disclose potential causes of GBS, i.e., the spontaneous reporting of suspected adverse drug reactions, self-controlled case series and case-control analysis, raises public health service-related questions about preferential or alternative procedures when facing early detection of a potential excess risk of GBS. It would appear that methodological issues and logistic elements related to the question to be answered are paramount. Speed in activating surveillance resources may constitute a key issue. Self-controlled case-series analysis in New York based on a list of 150 active-reporting neurologists and 2495 passive-reporting neurologists based in neurology departments, was considered expensive [35]. Our system, relying on hospital neurology departments, took advantage of the National Health Care Services which, on a geographical residential basis, covered well-defined populations, was underpinned by a small number of neurologists and was conducted at no extra cost. Spain's National Health Care system is operated by regional authorities and the AEMPS is a state-owned institution. The Spanish neurologist network was intensively active during the A(H1N1)pdm09 campaign, i.e., though the low monthly rates in 2010 and 2011 might have been related to underreporting. Reduction of surveillance to the November 2009-March 2010 period or express official support from the regional authorities for the purpose of incorporating public health missions in neurology departments might have improved GBS surveillance.

It would appear that GBS case-control studies using population controls and embodied in a hospital- and population-based network may be the best alternative for populations covered by publicly operated medical systems. This option does not exclude the addition of other procedures, such as self-controlled GBS case series, whether or not nested within an immunised cohort. At all events, knowledge of the GBS epidemiology in the study population is advantageous, particularly because asymmetry of exposure and confounder measurement in non-high-risk periods or among controls appears to be inevitable. Although $\mathrm{A}(\mathrm{H} 1 \mathrm{~N} 1) \mathrm{pdm} 09$ monovalent vaccine is no longer in use, its strain has been incorporated in the seasonal vaccines of the following years, so that our study results are still of practical significance. All things considered, an effective influenza vaccine might reduce GBS incidence through reductions in ILI-RTI infections, a far more frequent antecedent to GBS than is vaccination, as shown by our results.

\section{Conclusions}

We conclude that increased GBS incidence due to A(H1N1)pdm09 or TIV immunisations during 2010-2011 over background GBS is unlikely. Efficient GBS surveillance requires the local support of public health authorities and methodological updates, in line with the designated purpose in each case.

\section{Ethics and consent to participate}

This research was approved by the Comité de Ética en la Investigación y Bienestar Animal del Instituto de Salud Carlos III, with the reference number CEI PI 20_2009. All patients, with no exceptions, gave their informed consent.

\section{Consent to publish}

Not applicable.

\section{Availability of data and materials}

We will offer our surveillance database duly anonymised, upon request to the corresponding author. As for the cases of Guillain-Barré syndrome coded in the National Hospital In-patient Registry we do not have permission from the Spain's Ministry of Health to share it with third parties. 


\section{Abbreviations}

A(H1N1)pdm09: pandemic A(H1N1)2009 virus; AEMPS: Spanish Agency of Medicines and Medical Devices (Agencia Española de Medicamentos y Productos Sanitarios); Cl: confidence interval; GBS: Guillain-Barré syndrome; GTI: gastrointestinal tract infection; ICD-9-CM: International Classification of Diseases, Ninth Revision, Clinical Modification; ILI-RTI: influenza-like or respiratory tract infection; IVGG: intravenous gammaglobulin; MFS: Miller-Fisher syndrome; NINDS: National Institutes of Neurological Disorders and Stroke; OR: odds ratio; TIV: seasonal trivalent influenza vaccine.

\section{Competing interests}

The authors declare that they have no competing interests.

\section{Authors' contributions}

EAC assisted in data collection and analysis and with writing manuscript. JA built the database, assisted with data collection and network management. FJGL. validated data and wrote parts of manuscript linked to In-Patient registry and substantially assisted in writing the first and revised manuscript versions. JRAC notified and commented manuscript. FA helped with data collection. CC1 collected data and commented manuscript. CC2 collected data and commented manuscript. JIC helped in surveillance design and commented manuscript. JD reported cases and commented manuscript. MDFP reported cases and repeatedly commented manuscript. OF, notified. JAGM reported data, validated registry data, commented manuscript. RGM reported data and commented manuscript. DM initiated study, revised vaccines data, commented manuscript. JP reported data and commented manuscript. FJRR reported data and commented text. MRT supervised notification and commented manuscript, JdePC conceived the study with DM, supervised process, coordinated and wrote the first draft. All authors read and approved the final manuscript.

\section{Acknowledgments}

The authors would like to thank their colleagues at the National Centre for Epidemiology, Dr. Rafael Fernández-Cuenca Gómez for access to National In-Patient Registry data, Dr. Aurora Limia Sánchez,from the Spain's Ministry of Health, Social Services, and Equity for her assistance, Dr. Javier Damián Moreno for his comments on the manuscript and Dr. Amparo Larrauri Cámara, Concepción Delgado Sanz and Silvia Jiménez Jorge for their help in information on Spain's influenza surveillance.

\section{Funding}

No funding was obtained for this study.

\section{Author details}

'National Centre for Epidemiology, CIBERNED, Carlos III Health Institute, Madrid, Spain. ${ }^{2}$ Neurology Department, Miguel Servet University Hospital, Zaragoza, Spain. ${ }^{3}$ Neuromuscular Unit, Neurology Department, Bellvitge University Hospital, Bellvitge, Biomedical Research Institute (Institut d'Investigació Biomèdica de Bellvitge/IDIBELL), L'Hospitalet de Llobregat, Spain. ${ }^{4}$ Neurology Department, Severo Ochoa University Hospital, Leganés, Madrid, Spain. ${ }^{5}$ Epidemiology Department, Regional Ministry of Health, Madrid Autonomous Region, Spain. ${ }^{6}$ Neurology Department, General Hospital, Segovia, Spain. ${ }^{7}$ Neurology Department, Virgen de las Nieves University Hospital, Granada, Spain. ${ }^{8}$ Neurology Department, Carlos Haya University Hospital, Málaga, Spain. ${ }^{9}$ Neurology Department, Puerta de Hierro University Hospital, Majadahonda, Madrid, Spain. ${ }^{10}$ Neurology Department, Virgen de la Salud Hospital, Toledo, Spain. ${ }^{11}$ Spanish Medicines \& Medical Devices Agency (Agencia Española de Medicamentos y Productos Sanitarios), Madrid, Spain. ${ }^{12}$ Neurology Department, University Teaching Hospital Clínico, Santiago de Compostela (Corunna), Spain. ${ }^{13}$ Neurology Department, La Paz University Hospital, Madrid, Spain.

Received: 14 August 2015 Accepted: 12 May 2016

Published online: 21 May 2016

\section{References}

1. Yuki N, Hartung HP. Guillain-Barré syndrome. N Engl J Med. 2012;366(24): 2294-304.

2. Forsberg A, Press R, Einarsson U, de Pedro-Cuesta J, Holmqvist LW. Disability and health-related quality of life in Guillain-Barré syndrome during the first two years after onset: a prospective study. Clin Rehabil. 2005;19(8):900-9.
3. Hurwitz ES, Schonberger LB, Nelson DB, Holman RC. Guillain-Barré syndrome and the 1978-1979 influenza vaccine. N Engl J Med. 1981;304(26):1557-61.

4. Safranek TJ, Lawrence DN, Kurland LT, Culver DH, Wiederholt WC, Hayner NS, et al. Reassessment of the association between Guillain-Barré syndrome and receipt of swine influenza vaccine in 1976-1977: results of a two-state study. Expert Neurology Group. Am J Epidemiol. 1991;133(9):940-51.

5. Lasky T, Terracciano GJ, Magder L, Koski CL, Ballesteros M, Nash D, et al. The Guillain-Barré syndrome and the 1992-1993 and 1993-1994 influenza vaccines. N Engl J Med. 1998;339(25):1797-802.

6. Whitaker HJ, Farrington CP, Spiessens B, Musonda P. Tutorial in biostatistics: the self-controlled case series method. Stat Med. 2006;25(10):1768-97.

7. Glanz JM, McClure DL, Xu S, Hambidge SJ, Lee M, Kolczak MS, et al. Four different study designs to evaluate vaccine safety were equally validated with contrasting limitations. J Clin Epidemiol. 2006;59(8):808-18.

8. McClure DL, Glanz JM, Xu S, Hambidge SJ, Mullooly JP, Baggs J. Comparison of epidemiologic methods for active surveillance of vaccine safety. Vaccine. 2008;26(26):3341-5.

9. Salmon DA, Proschan M, Forshee R, Gargiullo P, Bleser W, Burwen DR, et al. Association between Guillain-Barré syndrome and influenza A (H1N1) 2009 monovalent inactivated vaccines in the USA: a meta-analysis. Lancet. 2013; 381(9876):1461-8

10. Dodd CN, Romio SA, Black S, Vellozzi C, Andrews N, Sturkenboom M, et al. International collaboration to assess the risk of Guillain Barré Syndrome following Influenza A (H1N1) 2009 monovalent vaccines. Vaccine. 2013; 31(40):4448-58.

11. Martín Arias LH, Sanz R, Sáinz M, Treceño C, Carvajal A. Guillain-Barré syndrome and influenza vaccines: a meta-analysis. Vaccine. 2015;33(31):3773-8.

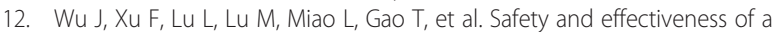
2009 H1N1 vaccine in Beijing. N Engl J Med. 2010;363(25):2416-23.

13. Bardage C, Persson I, Ortqvist A, Bergman U, Ludvigsson JF, Granath F. Neurological and autoimmune disorders after vaccination against pandemic influenza A (H1N1) with a monovalent adjuvanted vaccine: population based cohort study in Stockholm, Sweden. BMJ. 2011;343:d5956.

14. Ghaderi S, Gunnes N, Bakken I, Magnus P, Trogstad L, Håberg SE. Risk of Guillain-Barré syndrome after exposure to pandemic influenza A(H1N1)pdm09 vaccination or infection: a Norwegian population-based cohort study. Eur J Epidemiol. 2016;31(1):67-72.

15. Kim C, Rhie S, Suh M, Kang DR, Choi YJ, Bae GR, et al. Pandemic influenza A vaccination and incidence of Guillain-Barré syndrome in Korea. Vaccine. 2015;33(15):1815-23.

16. Burwen DR, Sandhu SK, MaCurdy TE, Kelman JA, Gibbs JM, Garcia B, et al. Surveillance for Guillain-Barré syndrome after influenza vaccination among the Medicare population, 2009-2010. Am J Public Health. 2012;102(10):1921-7.

17. Savulescu C, Jiménez-Jorge S, de Mateo S, Ledesma J, Pozo F, Casas I, et al. Effectiveness of the 2010/11 seasonal trivalent influenza vaccine in Spain: preliminary results of a case-control study. Euro Surveill. 2011;16(11):pii:19820.

18. Jiménez-Jorge S, de Mateo S, Pozo F, Casas I, García Cenoz M, Castilla J, et al. Early estimates of the effectiveness of the 2011/12 influenza vaccine in the population targeted for vaccination in Spain, 25 December 2011 to 19 February 2012. Euro Surveill. 2012;17(12):pii:20129.

19. Valenciano M, Kissling E, Cohen JM, Oroszi B, Barret AS, Rizzo C, et al. Estimates of pandemic influenza vaccine effectiveness in Europe, 20092010: results of Influenza Monitoring Vaccine Effectiveness in Europe (IMOVE) multicentre case-control study. PLoS Med. 2011;8(1):e1000388.

20. Ministerio de Sanidad y Consumo. Real Decreto 2210/1995, de 28 diciembre, por el que se crea la red nacional de vigilancia epidemiológica. http://www. boe.es/diario_boe/txt.php?id=BOE-A-1996-1502. Boletín Oficial del Estado 24 enero 1996, núm. 21, 2153-2158. 28-12-1995. 1502. Accessed 3 Mar 2016.

21. Cuadrado JL, de Pedro-Cuesta J, Ara JR, Cemillán CA, Díaz M, Duarte J, et al. Guillain-Barré syndrome in Spain, 1985-1997: epidemiological and public health views. Eur Neurol. 2001;46(2):83-91.

22. Cuadrado JL, de Pedro-Cuesta J, Ara JR, Cemillán CA, Díaz M, Duarte J, et al. Public health surveillance and incidence of adulthood Guillain-Barré syndrome in Spain, 1998-1999: the view from a sentinel network of neurologists. Neurol Sci. 2004;25(2):57-65.

23. Asbury AK, Arnason BG, Karp HR, McFarlin DE. Criteria for diagnosis of Guillain-Barré syndrome. Ann Neurol. 1978;3(6):565-6.

24. Sejvar JJ, Kohl KS, Gidudu J, Amato A, Bakshi N, Baxter R, et al. Guillain-Barré syndrome and Fisher syndrome: case definitions and guidelines for collection, analysis, and presentation of immunization safety data. Vaccine. 2011;29(3):599-612. 
25. Ministerio de Sanidad Servicios Sociales e Igualdad. Registro de Altas de los Hospitales Generales del Sistema Nacional de Salud. CMBD. Norma Estatal. www.msssi.gob.es. 2014. 25-2-2014. Accessed 3 Mar 2016.

26. Ulm K. A simple method to calculate the confidence interval of a standardized mortality ratio (SMR). Am J Epidemiol. 1990;131(2):373-5.

27. Cheng Q, Jiang GX, Fredrikson S, Link H, de Pedro-Cuesta J. Epidemiological surveillance of Guillain-Barré syndrome in Sweden, 1996-1997. Network members of the Swedish GBS Epidemiology Study Group. Acta Neurol Scand. 2000;101(2):104-10

28. Funch D, Holick C, Velentgas P, Clifford R, Wahl PM, McMahill-Walraven C, et al. Algorithms for identification of Guillain-Barré Syndrome among adolescents in claims databases. Vaccine. 2013;31(16):2075-9.

29. Stowe J, Andrews N, Wise L, Miller E. Investigation of the temporal association of Guillain-Barré syndrome with influenza vaccine and influenzalike illness using the United Kingdom General Practice Research Database. Am J Epidemiol. 2009;169(3):382-8.

30. Kwong JC, Vasa PP, Campitelli MA, Hawken S, Wilson K, Rosella LC, et al. Risk of Guillain-Barré syndrome after seasonal influenza vaccination and influenza health-care encounters: a self-controlled study. Lancet Infect Dis. 2013;13(9):769-76.

31. Iqbal S, Li R, Gargiullo P, Vellozzi C. Relationship between Guillain-Barré syndrome, influenza-related hospitalizations, and influenza vaccine coverage. Vaccine. 2015;33(17):2045-9.

32. de Wals P, Deceuninck G, Toth E, Boulianne N, Brunet D, Boucher RM, et al. Risk of Guillain-Barré syndrome following H1N1 influenza vaccination in Quebec. JAMA. 2012;308(2):175-81.

33. Galeotti F, Massari M, D'Alessandro R, Beghi E, Chio A, Logroscino G, et al. Risk of Guillain-Barré syndrome after 2010-2011 influenza vaccination. Eur J Epidemiol. 2013;28(5):433-44.

34. Dieleman J, Romio S, Johansen K, Weibel D, Bonhoeffer J, Sturkenboom M. Guillain-Barré syndrome and adjuvanted pandemic influenza A (H1N1) 2009 vaccine: multinational case-control study in Europe. BMJ. 2011;343:d3908.

35. Giambrone GP, Zansky SM, Eidson M, Duncan PG, McNutt LA, Birkhead GS, Guillain-Barré syndrome surveillance during National Influenza Vaccination Campaign, New York, U.S.A., 2009. Emerg Infect Dis. 2013;19(12):1956-62.

\section{Submit your next manuscript to BioMed Central and we will help you at every step:}

- We accept pre-submission inquiries

- Our selector tool helps you to find the most relevant journal

- We provide round the clock customer support

- Convenient online submission

- Thorough peer review

- Inclusion in PubMed and all major indexing services

- Maximum visibility for your research

Submit your manuscript at www.biomedcentral.com/submit

) Biomed Central 